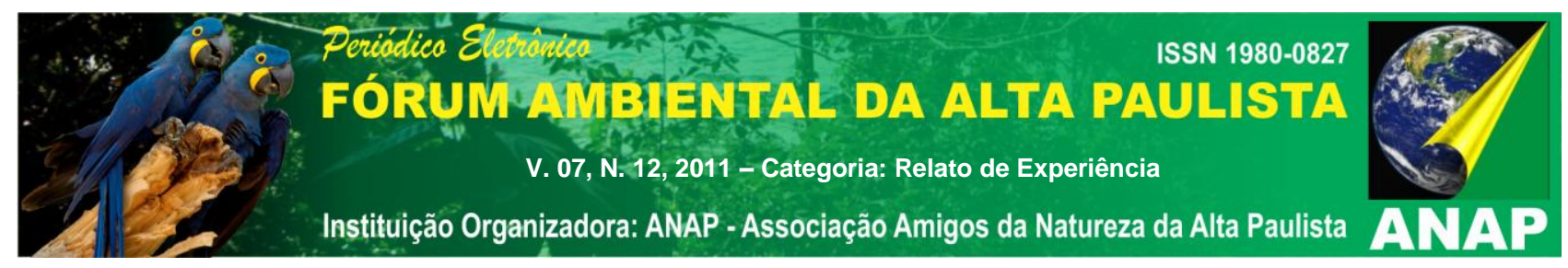

\title{
TRABALHO DE COMBATE ÀS PERDAS DE ÁGUA
}

\section{Antonio Rodrigues da Grela Filho ${ }^{1}$}

\author{
André Locanco Cavalini ${ }^{1}$
}

\section{Marco Aurélio Saraiva Chakur ${ }^{1}$}

RESUMO: Relato de experiência do trabalho de combate às perdas de água nos sistemas públicos de abastecimento dos 83 Municípios e 42 Distritos, totalizando 125 comunidades.

Palavras chave: Água - perdas - monitoramento

\section{INTRODUÇÃO}

Desde 1995, a Unidade de Negócio Baixo Tietê e Grande da Sabesp vem trabalhando para reduzir as perdas totais (reais e aparentes).

Naquele ano as perdas totais atingia $40 \%$, ou seja, 200 litros/ramal/dia.

Diante da situação critica, foram adotadas várias ações:

1. Instalações de medidores em $100 \%$;

2. Instalações de macros medidores na produção em 100\%;

3. Instalações de válvulas reguladoras de pressões;

4. Informatizações das maiores cidades (acima de 3.00 ligações);

5. Monitoramentos noturnos;

6. Cálculos com base no litros/ramal/dia;

7. Comprometimento das pessoas;

8. Substituições de redes e ramais;

\footnotetext{
${ }^{1}$ Companhia de Saneamento Básico do Estado de São Paulo- antoniorgf@sabesp.com.br
} 


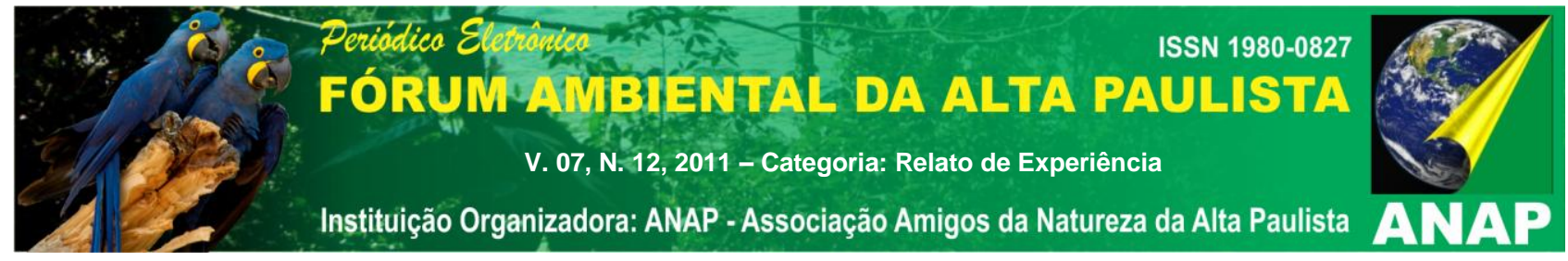

9. Fator pesquisa noturno.

O resultado de todo o trabalho foi a diminuição para $19 \%$, ou seja, 100 litros/ramal/dia. Isto significa que restam as perdas de $9 \%$ para ser combatida, porque $6 \%$ na hidrometria e $4 \%$ nos vazamentos são praticamente impossíveis.

O Brasil perde aproximadamente $50 \%$ da água produzida.

São dezesseis anos de trabalho, com grande envolvimento. A grande dificuldade é manter o resultado.

$\mathrm{Na}$ redução deixamos de perder 23 milhões de litros por dia, suficiente para abastecer as cidades de Fernandópolis e Novo Horizonte.

Com certeza é um dos melhores indicadores do país, que já serviu para visitações de alunos do curso JICA - Organização Internacional e, grupo de engenheiros de outros países que buscaram informações a respeito do trabalho.

\section{OBJETIVO GERAL}

O objetivo é de reduzir as perdas cada vez mais, diminuindo os custos de produção/distribuição água. Além disso, é possível postergar investimentos poços/reservatórios.

Os recursos são os mesmos, mas se evitamos perdas, podemos direcionar mais recursos para os esgotos.

Além disso, também garantimos um melhor atendimento.

Garantimos as preservações dos mananciais (superficiais/subterrâneos), que é a garantia de abastecimento no futuro.

\section{OBJETIVOS ESPECÍFICOS}

As perdas são controladas com base naquilo que é produzido (macro) confrontando com o que é vendido (micro).

Importante medir. Quem não sabe o que vende, não sabe o que perde. 


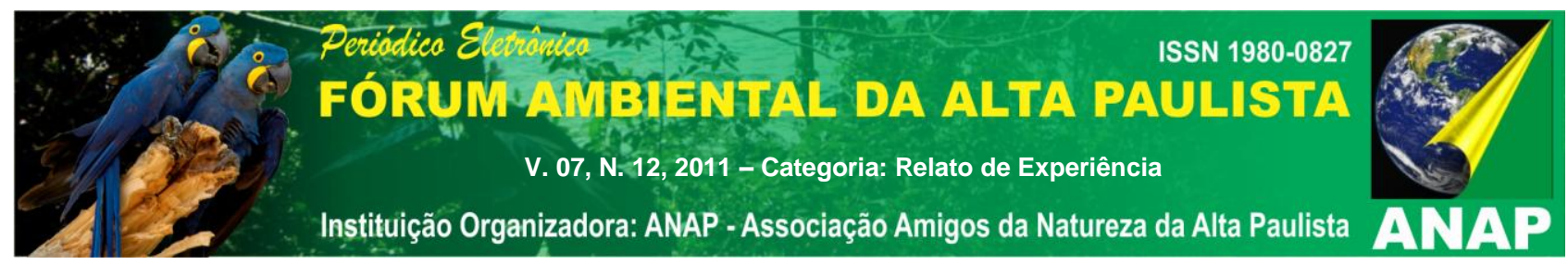

O entendimento de cada sistema, analisando o diagnóstico de cada cidade é de extrema importância para saber cada situação.

Nenhuma empresa de saneamento conquista a credibilidade técnica, financeira e de qualidade se trabalhar com perdas altas.

Esta pratica foi implantada na Unidade de Negócio do Baixo Tietê e Grande com sede em Lins no sentido de cada vez mais apresentar resultados satisfatórios.

Trabalhamos muito com as pessoas. Apesar de toda tecnologia, muitas ações de combate as perdas depende de cada técnico que esta no controle operacional durante 0 dia todo. Muitas vezes é um alerta que faz a diferença.

Apesar da qualidade do medidor, dos materiais que são vendidos no Brasil, não podemos deixar que as perdas sejam justificadas. Precisamos de resultado com base no esforço das pessoas.

Uma comunidade com perda alta pode sofrer com falta.

No final de semana entre os dias 25 a 28 de agosto de 2011, a comunidade de Bento de Abreu com 960 ligações sofreu com interrupções fornecimento devido a um vazamento invisível. O problema foi totalmente solucionado na noite do dia 28, quando foi encontrado o vazamento que não deixava a água chegar no reservatório.

Desta forma, é preciso concentrar todos os esforços no sentido de diagnosticar, mas recuperar qualquer vazamento encontrado.

\section{METODOLOGIA}

A metodologia do controle de perdas inicia-se com o fator de pesquisa diário nos sistemas informatizados, ou a cada 10 dias nos sistemas controlados pela medição noturna no período das 01.00 às 02.horas da madrugada.

O fator de pesquisa é dividir o volume medido no período acima, que chamamos de vazão mínima noturna pela vazão média, multiplicado por 100. O resultado não deve ser maior que 20, porque sendo, existe algum vazamento invisível.

No sistema informatizado, basta controlar a vazão mínima a qualquer hora, sempre considerando o período da madrugada. 

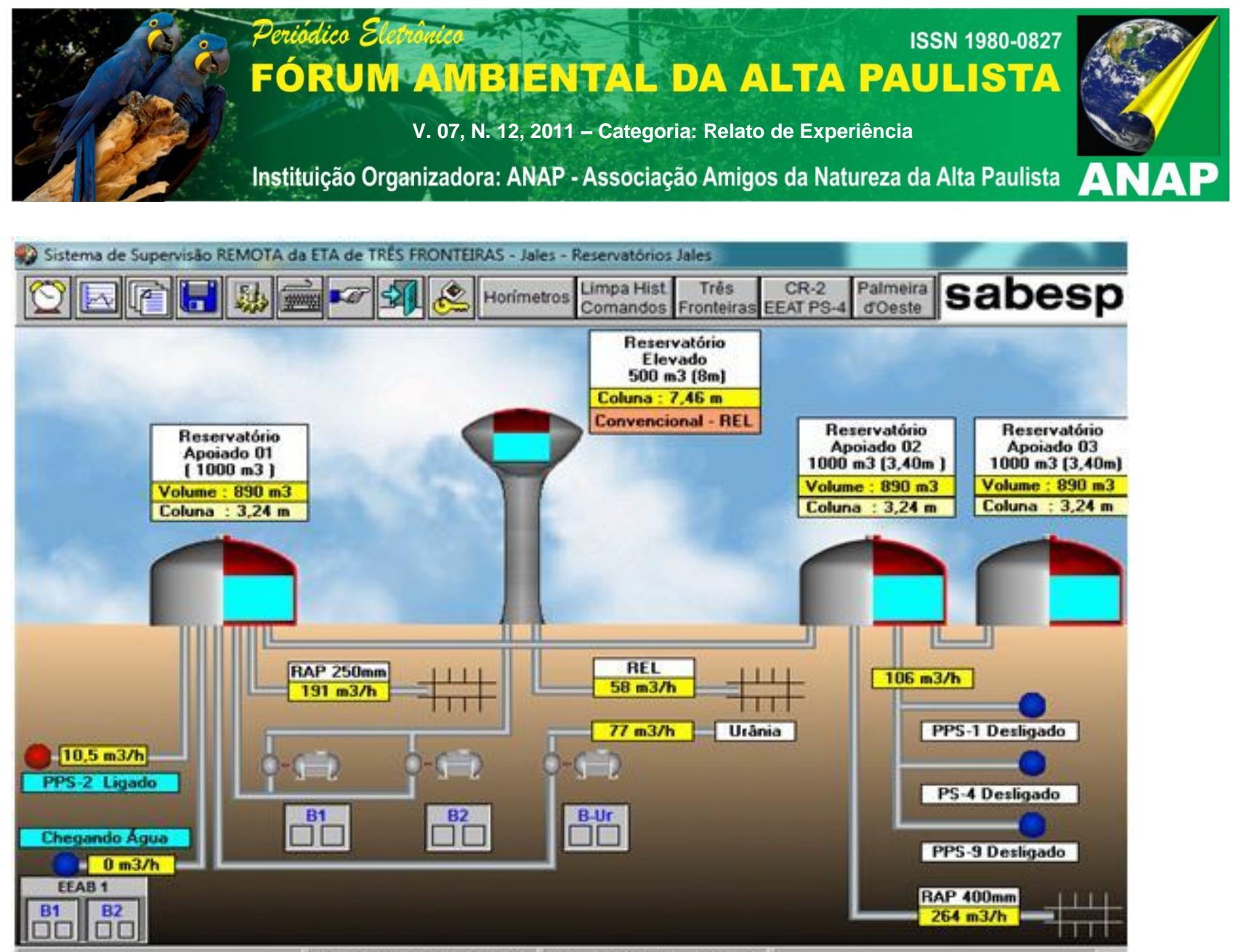

\begin{tabular}{|l|l|}
\hline Três Fronkeisas Desconectada & Fevereivo 09, 2011 11:1904 \\
\hline
\end{tabular}

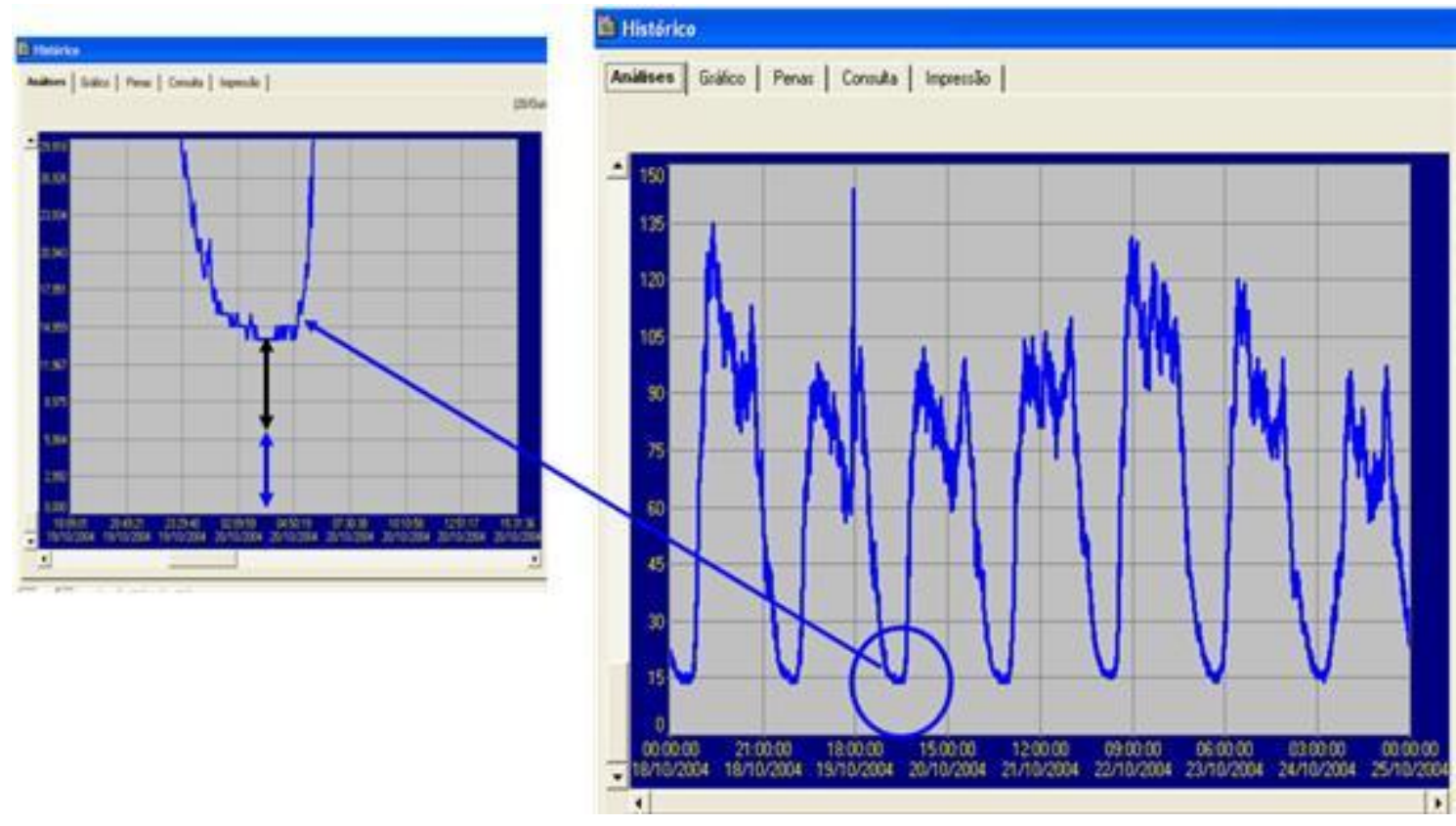



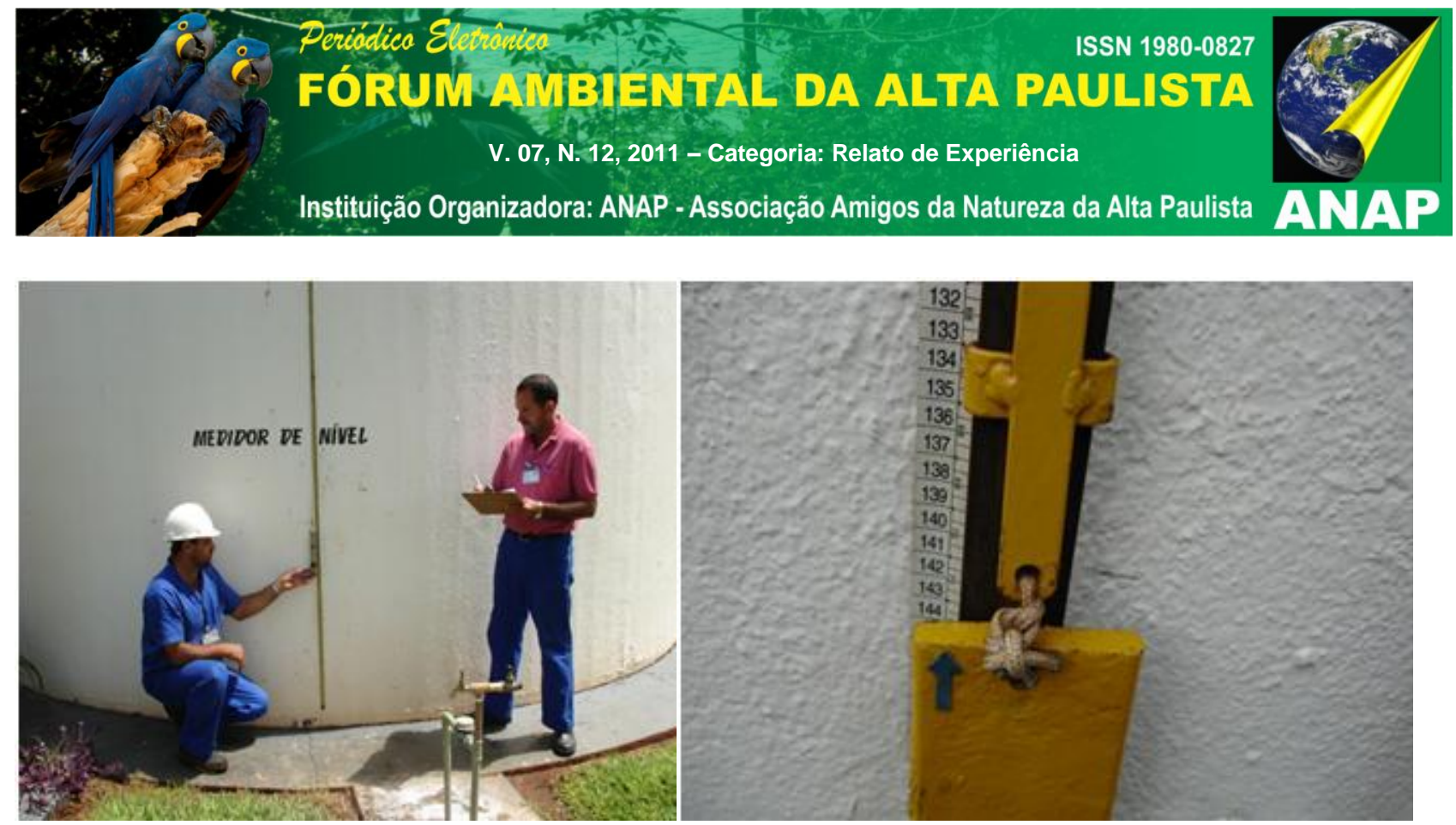

Um outro controle é a pressão de cada rede. Até 20 mca (metros por coluna água) é satisfatório. Ultrapassando o número, já deve ser instalada válvula reguladora, visando baixar a pressão. Evitando vazamentos.

Outra condição é a substituição de ramal. O conserto nem sempre traz o resultado esperado porque acaba vazando noutro lugar. A substituição de redes também é importante, considerando a vida útil.
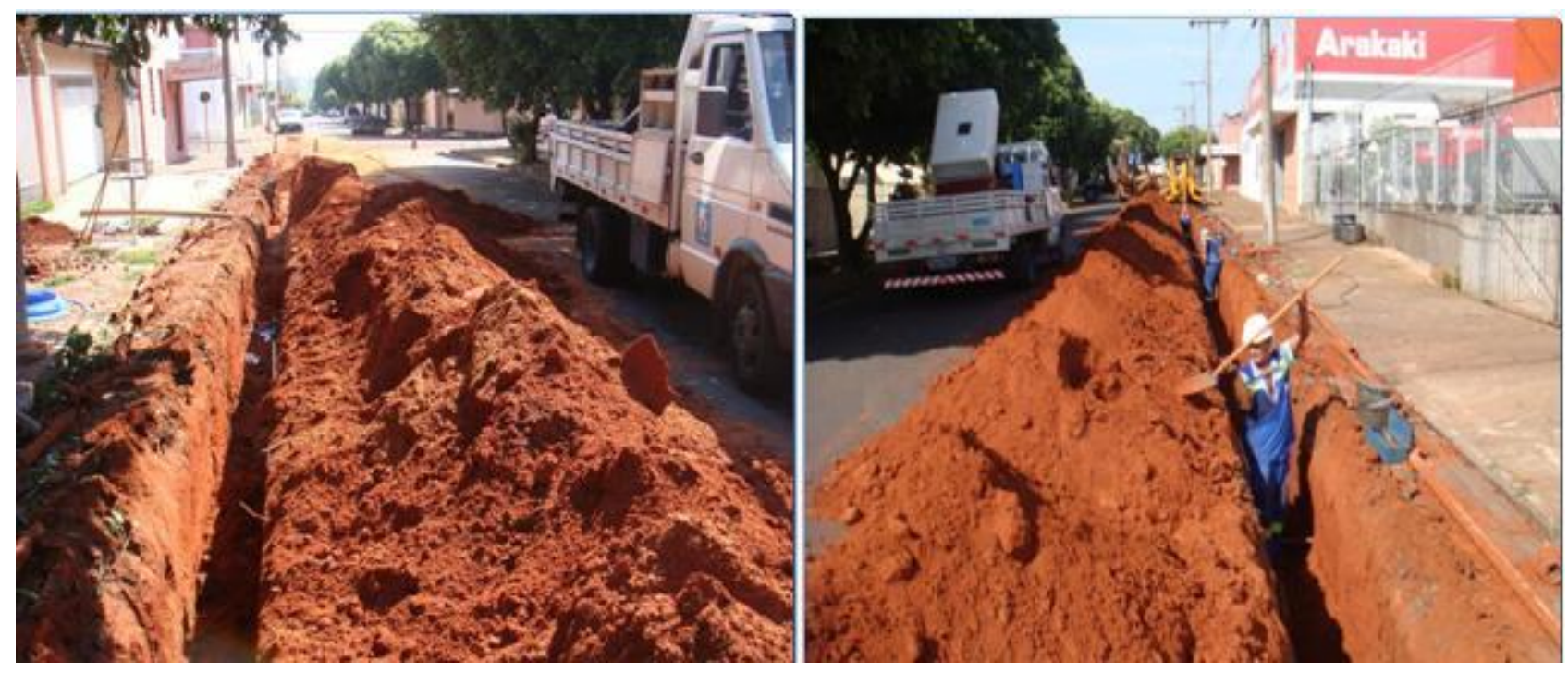

A gestão da hidrometria, que é o controle dos hidros parados com as substituições deve ser uma rotina.

Normalmente, o hidrômetro quando se encontra com utilização acima de 5 anos, começa apresentar defeitos, ou seja, diminuir o volume medido. 


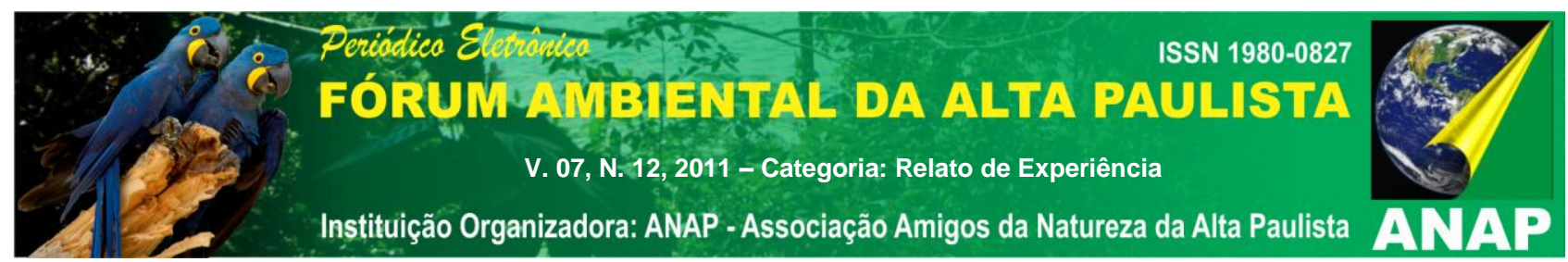

Outro controle importante, é separar as perdas reais (vazamentos) das perdas aparentes (comerciais) porque, caso contrario, poderá haver investimento errado. Este controle é fundamental para saber onde atacar.

Para o cálculo é preciso saber o número de habitantes, mais o número das ligações, que multiplicados pelos respectivos volumes chegamos de forma aproximada onde esta a perda real ou aparente.

A setorização é um outro trabalho importante. Na medida que faz a criação de distritos pitométricos, seccionando por setores, o controle é facilitado. Na pesquisa noturna, basta ir fechando os registros, que no controle informatizado já vai apresentando o quanto aquela região esta interferindo.

Controlar a região das incidências de vazamentos é uma pratica adotada no Japão, que é um dos melhores indicadores do mundo. Com este trabalho fica mais fácil direcionar a pesquisa quando a necessidade é muito grande.

Mas, o melhor método de cálculo é litros/ramal/dia. Uma comunidade com consumo de 1.000 litros por ligação/dia, falar em $20 \%$ são 200 litros, enquanto, noutro local com consumo de 500 litros por ligação/dia, falar em 20\% são 100 litros. Então, o ideal é controlar pelos litros/ramal/dia, conforme orientação de Allan Lambert (consultor mundial sobre perdas água), que trabalha para a IWA - InternationalWaterAssociation.

Segundo o consultor até 30 litros/ramal/dia é praticamente impossível detectar na pesquisa, devido às conexões existentes.

Quando falamos em ramal, estamos dizendo do colar existente na rede até o cavalete (hidrômetro).

Aplicar a metodologia acima, depende muito de cada técnico.

Resultado

\section{RESULTADO (S)}

O resultado foi a redução de $40 \%$ para $19 \%$, resultando em 23 milhões de litros água por dia. Isto significa deixar de gastar 19 mil reais/dia, aproximadamente 600 mil reais por mês, considerando o custo de 80 centavos por metro cúbico.

Existem locais de venda água em até 2,00 reais o metro cúbico. 


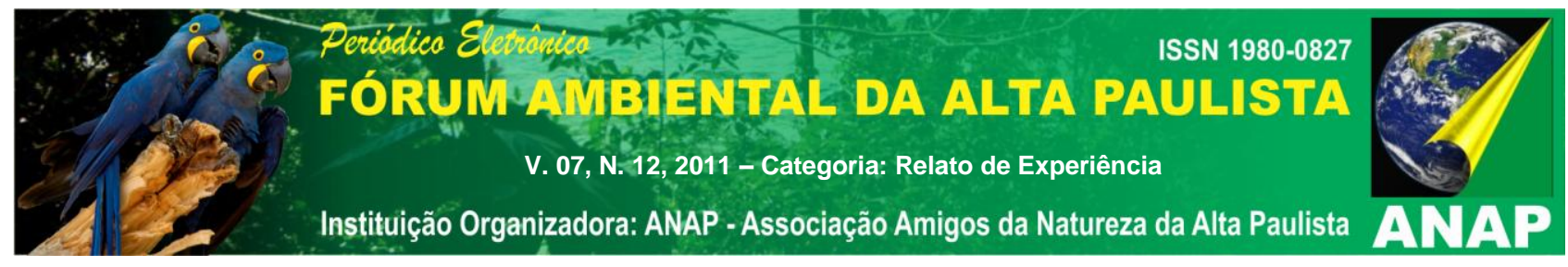

Além disso, deixamos de investir no aumento da produção (poços), também na reservarão (reservatórios), postergando as necessidades.

O maior resultado é o comprometimento das pessoas, entendendo a necessidade do trabalho de pesquisa.

A gestão dos hidrômetros também tem sido importante. Analisando os consumos baixos de 0 a $10 \mathrm{~m} 3 / \mathrm{mês}$, é possível detectar todos os parados. Também a preventiva que é substituir os hidros com mais de 8 anos.

Um exemplo é a cidade de Auriflama, que manteve o volume produzido, aumentando o volume vendido, decorrente da redução de perda. Apesar do aumento do número de ligações, não houve necessidade de aumentar a produção.

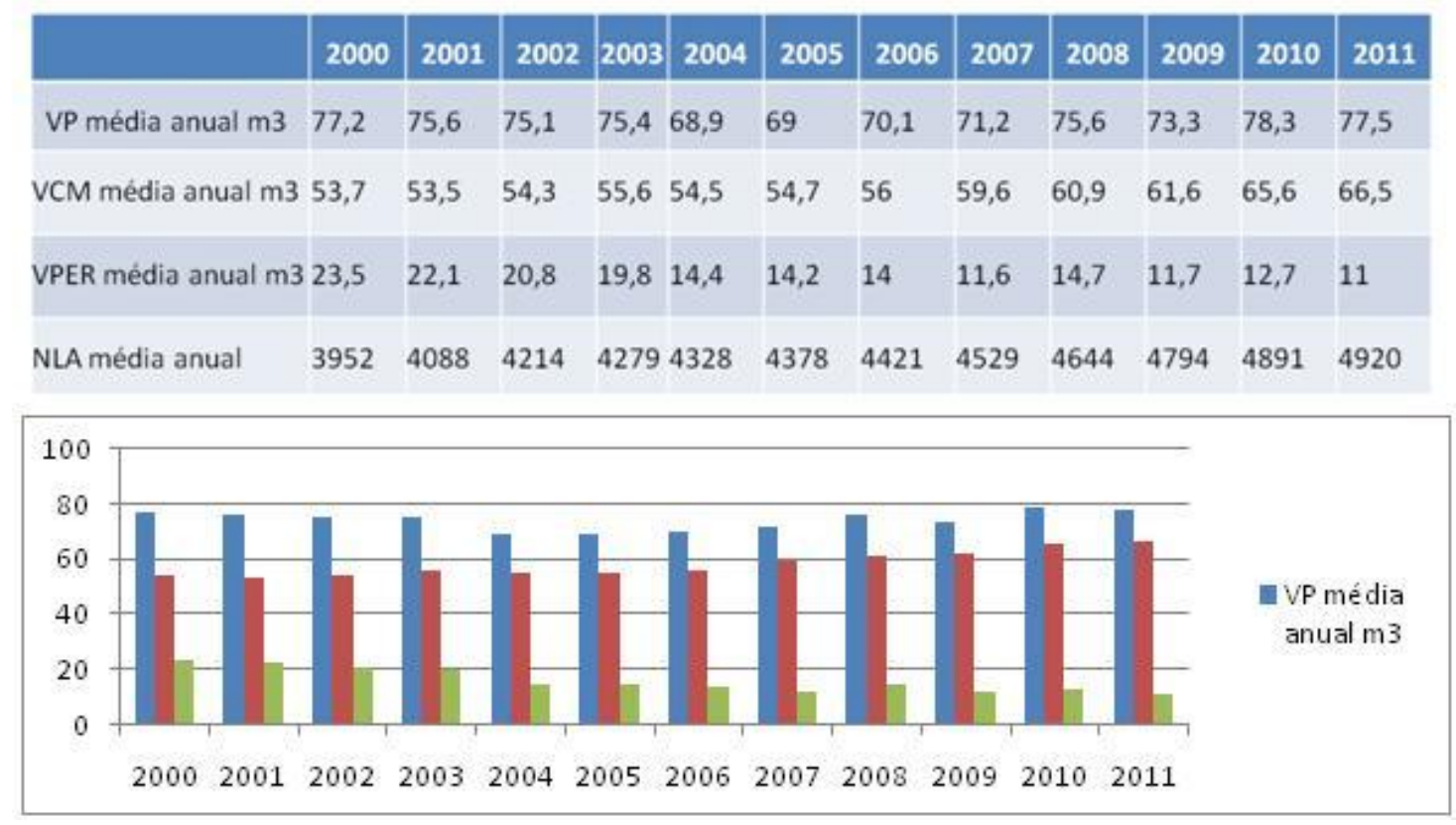

Todo o trabalho coloca a Unidade de Negócio do Baixo Tietê e Grande como uma das melhores regiões do Brasil em perdas água.

\section{CONSIDERAÇÕES FINAIS}

É um trabalho importantíssimo na área do saneamento. Muitas cidades sofrem com a falta água pela inexistência controle perdas. 


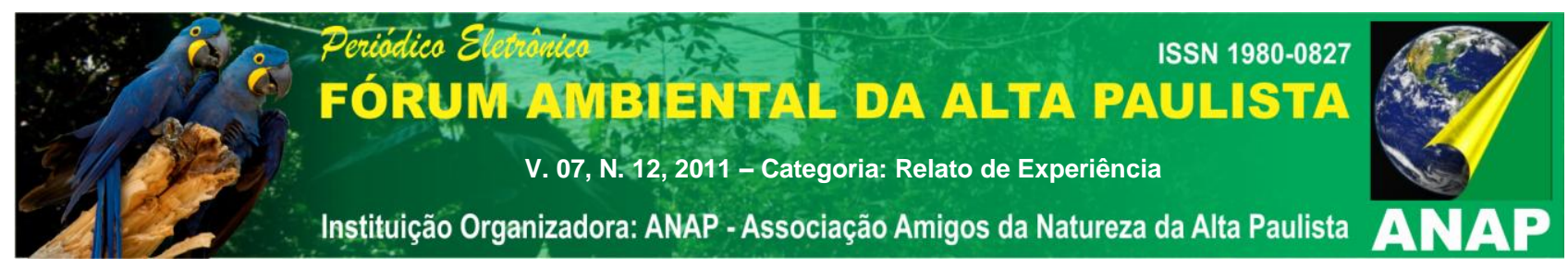

Outras investem nos sistemas de forma desnecessária, que poderia ser evitado com o trabalho combate as perdas.

É preciso muita persistência.

Baixar de $40 \%$ para $25 \%$ não é tão difícil, mas depois baixar para $19 \%$, manter pelo menos já exige um esforço muito grande.

Combater perdas é mais transpiração.

Mas, vale a pena o trabalho.

O meio ambiente agradece. A viabilidade economia aumenta. A população é melhor atendida.

\section{REFERÊNCIAS}

COELHO, Adalberto Cavalcanti. Medição de Água e Controle de Perdas. São Paulo: ABES, 1983.

SABESP. Manual de Operação e Combate de Perdas. 